\title{
Cost/Benefit Analysis
}

National Cancer Institute

\section{Source}

National Cancer Institute. Cost/Benefit Analysis. NCI Thesaurus. Code C16472.

An analysis of the cost effectiveness of different alternatives in order to see whether the benefits outweigh the costs 